\title{
Effect of Beta Low Irradiation Doses on the Filled PA66 Measured by Micro-indentation Test
}

\author{
Martin Ovsik $^{1, a}$, David Manas ${ }^{1, b}$, Miroslav Manas ${ }^{1, c}$, Michal Stanek ${ }^{1, d}$, Martin \\ Bednarik $^{1, e}$, Petr Krátký ${ }^{1, f}$. \\ ${ }^{1}$ Tomas Bata University in Zlin, TGM 5555, 76001 Zlin, Czech Republic

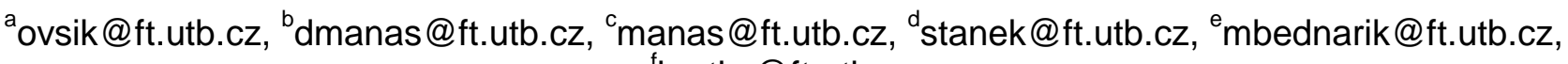 \\ tkratky@ft.utb.cz
}

Keywords: Polyamide 66, glass fiber, cross - linking, Micro - hardness, Depth Sensing Indentation.

\begin{abstract}
The presented article deals with the research of micro-mechanical properties in the surface layer of modified Polyamide 66 filled by $30 \%$ of glass fibers. These micro-mechanical properties were measured by the Depth Sensing Indentation - DSI method on samples which were non-irradiated and irradiated by different doses of the $\beta$ - radiation. Radiation doses used were 0,15 , 30 and $45 \mathrm{kGy}$ for filled Polyamide 66 with the $6 \%$ cross-linking agent (triallyl isocyanurate). Individual radiation doses caused structural and micro-mechanical changes which have a significant effect on the final properties of the polyamide 66 tested. The highest values of micro-mechanical properties were reached at radiation dose of $30 \mathrm{kGy}$, when the micro-hardness values increased by about $64 \%$. The aim of the article is to find out the influence of the radiation on the micro-hardness of the modified glass fiber-filled Polyamide 66 (PA66).
\end{abstract}

\section{Introduction}

Polyamides (PA) are semi-crystalline polymers. A distinction is made between two types. Polyamides made of one basic material (PA 6) and polyamides, which are made of 2 basic materials (PA 66). Polyamides have very good mechanical properties, are particularly tough and have excellent sliding and wear characteristics. [1]

Polyamide 66 (PA 66) is the most common extruded polyamide and offers a balanced combination of all typical characteristics of this group of materials. Polyamides are characterized by their possessing of hightensile strength, elasticity, tenacity and resistance to abrasion. These mechanical properties are maintained even under high temperatures and therefore, the polyamides can be used in temperatures up to $200{ }^{\circ} \mathrm{C}$ in applications of short-term. [1]

Polyamides are polymers whose repeating units are characterized by the amide group. Through radiation crosslinking, thermoplastic polyamides are turned into plastics which behave like elastomers over a wide temperature range. Crosslinking makes the originally thermoplastic product able to withstand considerably higher temperatures of up to $350{ }^{\circ} \mathrm{C}$. The dimensional stability under thermal stress is also improved. Radiation crosslinked polyamide can often replace thermosetting plastics or high-performance plastics such as PPS, PEI, LCP, etc. One application that has proved most useful over the years is radiation crosslinked components for the electrical industry, e.g. switch components, and the automotive industry, for instance components for the engine compartment. [2]

Common PA66, when exposed to the effect of the radiation cross-linking, degrades and its mechanical properties deteriorate. Using cross-linking agent TAIC (triallyl isocyanurate) produces a cross-linking reaction inside the PA66 structure. The utility properties of PA66 improve when the noncrystalline part of PA66 is cross-linked. [1 - 3]

The aim of this paper is to study the effect of ionizing radiation with different doses, on micromechanical properties of polyamide 66 (PA 66) with $30 \%$ of fiberglass reinforcement and compare these results with those of non-irradiated samples. The study is carried out due to the ever-growing employment of this type of polymer. 


\section{Experimental}

\section{Material and methods}

For this experiment polyamide 66 V-PTS-CREAMID-A3H7.2G6*M0129A, filled by 30\% glass fiber (PA66+30\%GF), that were supplied by PTS Plastics Technologies Service, Germany (filled by $30 \%$ glass fiber, PA66+TAIC) was used. The material already contained the special cross-linking agent TAIC - triallyl isocyanurate (6 volume \%), which should enable subsequent cross-linking by ionizing $\beta$-radiation. The prepared specimens were irradiated with doses of $0,15,30$ and $45 \mathrm{kGy}$ at BGS Beta-Gamma Service GmbH \& Co. KG, Germany.

The samples were made using the injection molding technology on the injection moulding machine Arburg Allrounder 420C. Processing temperature $245-295{ }^{\circ} \mathrm{C}$, mold temperature $85{ }^{\circ} \mathrm{C}$, injection pressure $80 \mathrm{MPa}$, injection rate $45 \mathrm{~mm} / \mathrm{s}$.

\section{Micro-indentation test}

Micro-indentation test were done using a Micro Combi Tester, CSM Instruments (Switzerland) according to the CSN EN ISO 14577. Load and unload speed was $2 \mathrm{~N} / \mathrm{min}$. After a holding time of $90 \mathrm{~s}$ at maximum load $1 \mathrm{~N}$ the specimens were unloaded. A holding time was $21600 \mathrm{~s}$ at the creep. The specimens were glued on metallic sample holders. Poisson's ratio $(v)$ of the polymer was 0.3.

The indentation hardness $\left(\mathrm{H}_{\mathrm{IT}}\right)$ was calculated as maximum load $\left(\mathrm{F}_{\max }\right)$ to the projected area of the hardness impression $\left(\mathrm{A}_{\mathrm{p}}\right)$ and the indentation modulus $\left(\mathrm{E}_{\mathrm{IT}}\right)$ is calculated from the Plane Strain modulus ( $\left.\mathrm{E}^{*}\right)$ using an estimated sample Poisson's ratio (v) according to: [4-5]

$$
H_{I T}=\frac{F_{\max }}{A_{p}} \quad \text { and } \quad E_{I T}=E^{*} \cdot\left(1-v_{s}^{2}\right)
$$

\section{Results and discussion}

The figure 1 shows a very important correlation between the force and the depth of the indentation. The correlations provide very valuable information on the behaviour of tested material and the modified surface layer.

The correlation between the force and the depth of the indentation in PA66+30\%GF also proved very interesting. It demonstrated the influence of radiation on the change of mechanical properties in the surface layer of specimens. The non-irradiated material showed low hardness as well as increasing impression of the indenter in the surface layer. On the contrary, the irradiated PA66+30\%GF showed considerably smaller depth of the impression of the indenter which can signify greater resistance of this layer to wear.
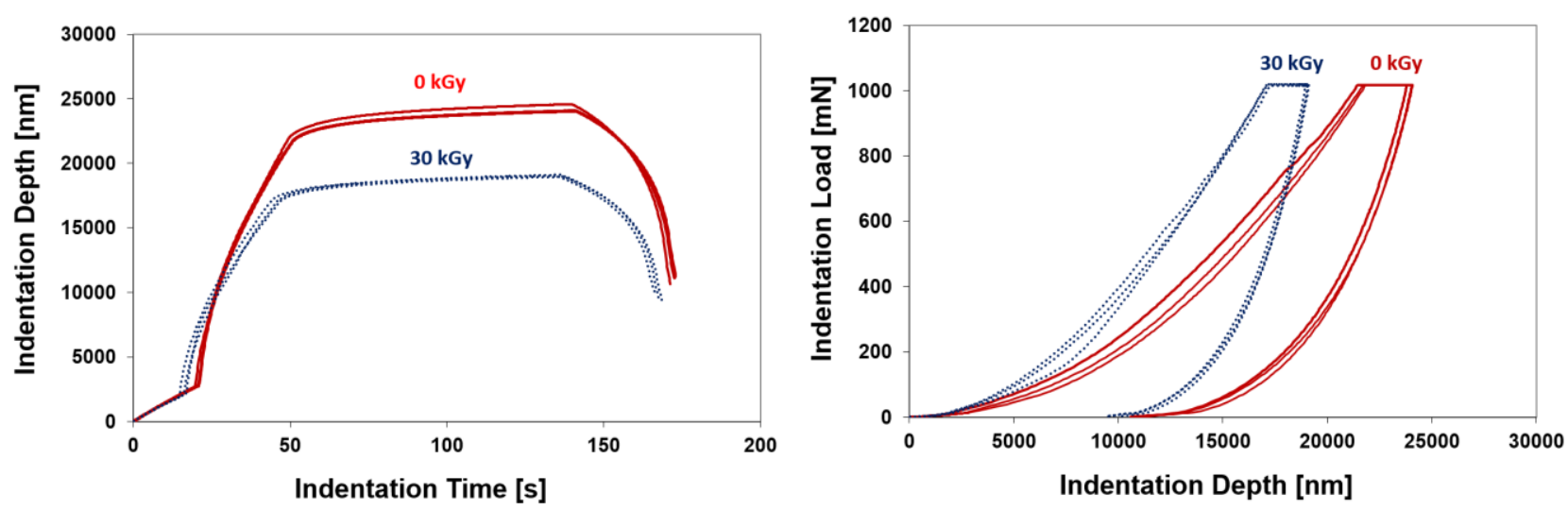

Fig. 1 Indentation characteristic of irradiated PA66+30\%GF 
The values measured during the micro-hardness test showed that the lowest values of indentation hardness and Vickers hardness were found for the non-irradiated PA66+30\%GF. On the contrary, the highest values of indentation hardness and Vickers hardness were obtained for PA66+30\%GF irradiated by a dose of $30 \mathrm{kGy}$ (by $64 \%$ higher in comparison with the non-irradiated PA66+30\%GF), as can be seen at Fig. 2 .

According to the results of measurements of micro-hardness, it was found that the highest values of indentation modulus of elasticity were achieved at the PA66+30\%GF irradiated with dose of 30 kGy (by 53\% higher than compared with non-irradiated PA66+30\%GF). On the contrary, the lowest values of the indentation modulus of elasticity were found for non-irradiated PA66+30\%GF, as is seen at Fig. 3.

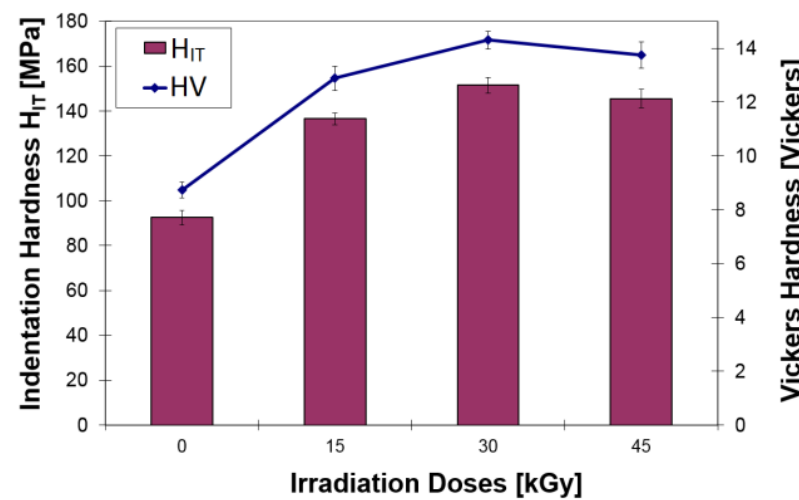

Fig. 2 Hardness vs. irradiation doses

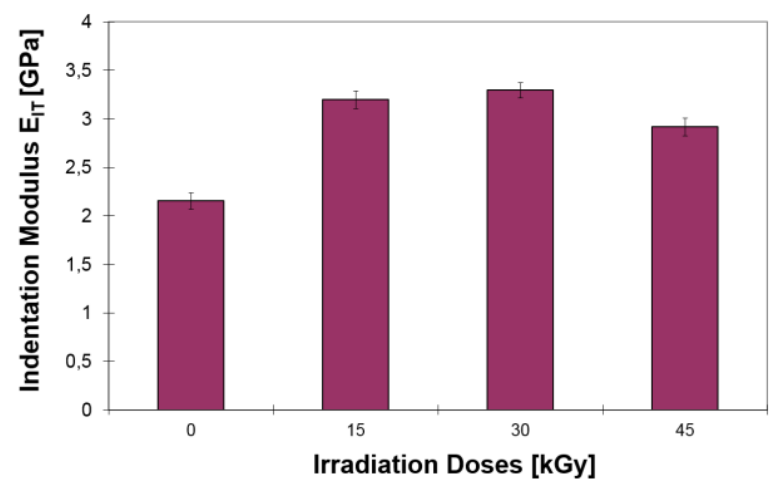

Fig. 3 Indentation modulus $\mathrm{E}_{\mathrm{IT}}$

Other important material parameters obtained during the micro-hardness test were elastic and plastic deformation work. The elastic deformation work $\mathrm{W}_{\mathrm{el}}$ determines the reaction of material to applied load with reversible deformation. The plastic part of the deformation work $\mathrm{W}_{\mathrm{pl}}$ defines toughness of the tested material (surface layer) and its resistance to plastic deformation.

The greatest values of plastic and elastic deformation work and coefficient of back deformation $\eta_{I T}$ were obtained for non-irradiated PA66+30\%GF. The lowest values of $\mathrm{W}_{\mathrm{el}}, \mathrm{W}_{\mathrm{pl}}$ and $\eta_{\text {IT }}$ were obtained for PA66+30\%GF irradiated with dose of $30 \mathrm{kGy}$. Radiation of specimens caused lower values of elastic as well as plastic deformation work which is apparent in Fig. 4.

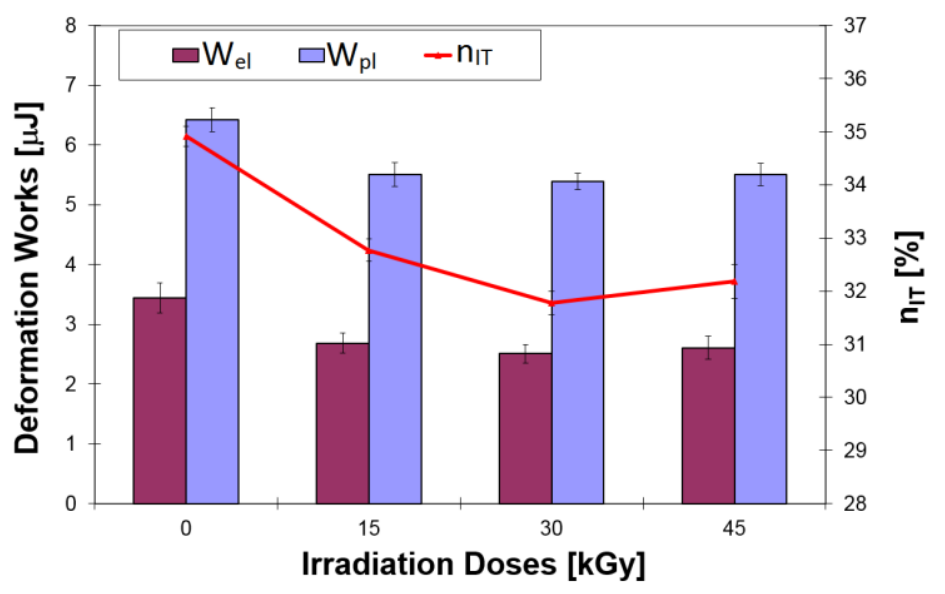

Fig. 4 Deformation work vs. irradiation dose

Higher radiation dose does not influence significantly the micro-hardness value. An indentation hardness increase of the surface layer is caused by irradiation cross-linking of the tested specimen. 
A closer look at the micro-hardness results reveals that when the highest radiation doses are used, micro-hardness decreases which can be caused by radiation induced degradation of the material.

\section{Conclusion}

The article is the assessment of micro-mechanical properties (micro-hardness) of the surface layer of modified PA66+30\%GF. The surface layer of the polymer material such as PA66+30\%GF is modified by $\beta$ - radiation with doses of 15,30 and $45 \mathrm{kGy}$.

Instrumented micro-hardness test of PA66+30\%GF beta irradiated samples was performed. After the beta radiation the amorphous part was cross linked what was accompanied with the radical increase of micro-hardness and indentation modulus of elasticity. The largest increase was observed in both cases using the doses of $30 \mathrm{kGy}$. The properties of surface layer of PA66+30\%GF were modified significantly by beta radiation improved.

Irradiation of PA $66+30 \% \mathrm{GF}$ with a $\beta$ - radiation influences the micro-mechanical properties in the following way:

- Radiation of specimens caused improvement values of indentation hardness and indentation modulus.

- The highest values of indentation hardness and indentation modulus were achieved at the PA66+30\%GF irradiated with dose of $30 \mathrm{kGy}$ (The micro-hardness values were increased by $64 \%$ and Stiffness of surface layer increased significantly by $53 \%$ as a result of radiation).

- Higher radiation dose does not influence the indentation hardness and indentation modulus significantly, on the contrary due to degradation processes the properties deteriorate.

- Values of indentation hardness and indentation modulus correspond to the deformation works.

The results of micro-mechanical properties of surface layer of modified PA66+30\%GF show that it can be used in more difficult applications in some industrial fields, in particular where there are high requirements for strength, stiffness and hardness of surface layer which appears to be the most suitable area of application.

\section{Acknowledgment}

This paper is supported by the internal grant of TBU in Zlin No. IGA/FT/2014/016 funded from the resources of specific university research and by the European Regional Development Fund under the project CEBIA-Tech No. CZ.1.05/2.1.00/03.0089 and Technology Agency of the Czech Republic as a part of the project called TA03010724 AV and EV LED luminaire with a higher degree of protection.

\section{References}

[1] M. Ovsik, D. Manas, M. Manas, M. Stanek, M. Hribova, K. Kocman, D. Samek, Irradiated Polypropylene Studied by Microhardness and WAXS, Chemicke listy, 106 (2012), 507-510.

[2] G. Zamfirova, V. Gaydarov, T. Zaharescu, L. G. Silva, Microindentation study of Electron Beam Irradiated Polyamide Samples, Chemicke Listy, 104 (2010), 283-286.

[3] D. Manas, M. Hribova, M. Manas, M. Ovsik, Stanek, Effect of Beta Irradiation on Morphology and Microhardness of Polypropylene Thin Layers, Thin Solid Films 530, (2013), 49-52.

[4] W.C. Oliver, G.M. Pharr, Measurement of Hardness and Elastic Modulus by Instrumented Indentation, Journal of Materials Research 19 (1), (2004), 1564 - 1583.

[5] A. Bolshakov and G. M. Pharr, Influences of pile-up on the measurement of mechanical properties by load and depth sensing indentation. J. Mater. Res. 13. (1998) p. 1049-1058. 